\section{Propranolol bei Hämangiomen als neue Perspektive}

- Dass der Betablocker Propranolol bei ausgedehnten Hämangiomen therapeutisch wirksam ist, wurde per Zufall entdeckt: Leauté-Labrèze et al. veröffentlichten 2008 im New England Journal of Medicine eine Kasuistik, bei der als Nebeneffekt einer Propranolol- und Prednisontherapie ein großes Gesichtshämangiom auffallend gut rückläufig war. Dr. Christina Mangold von der Kinderklinik Heilbronn stellte eigene Ergebnisse von rund 100 Kindern mit problematischen Hämangiomen vor, bei denen gute bis sehr gute Therapieerfolge unter Propanolol erzielt werden konnten. Die Kinder werden dabei für drei Tage stationär aufgenommen. Unter Monitorüberwachung erfolgt zunächst eine Dosierung mit $1 \mathrm{mg} / \mathrm{kg}$ KG pro Tag in drei Einzeldosen, bei guter Verträglichkeit wird die Dosis verdoppelt. Die Therapie (im
Off-Label-Use) erfolgt für insgesamt vier bis sechs Monate.

Wie der nicht-selektive Betablocker genau wirkt, ist derzeit unklar. Möglicherweise ist eine Engstellung der Kapillaren mit der Blockade einer weiteren Kapillarisierung sowie Vasokonstriktion und intravasaler Gerinnung verantwortlich. Eine neue Studie der Universitätskinderklinik Tübingen soll mehr Klarheit zur Effektivität dieser Behandlung bringen.

Mangold C. Propranolol bei Problemhämangiomen
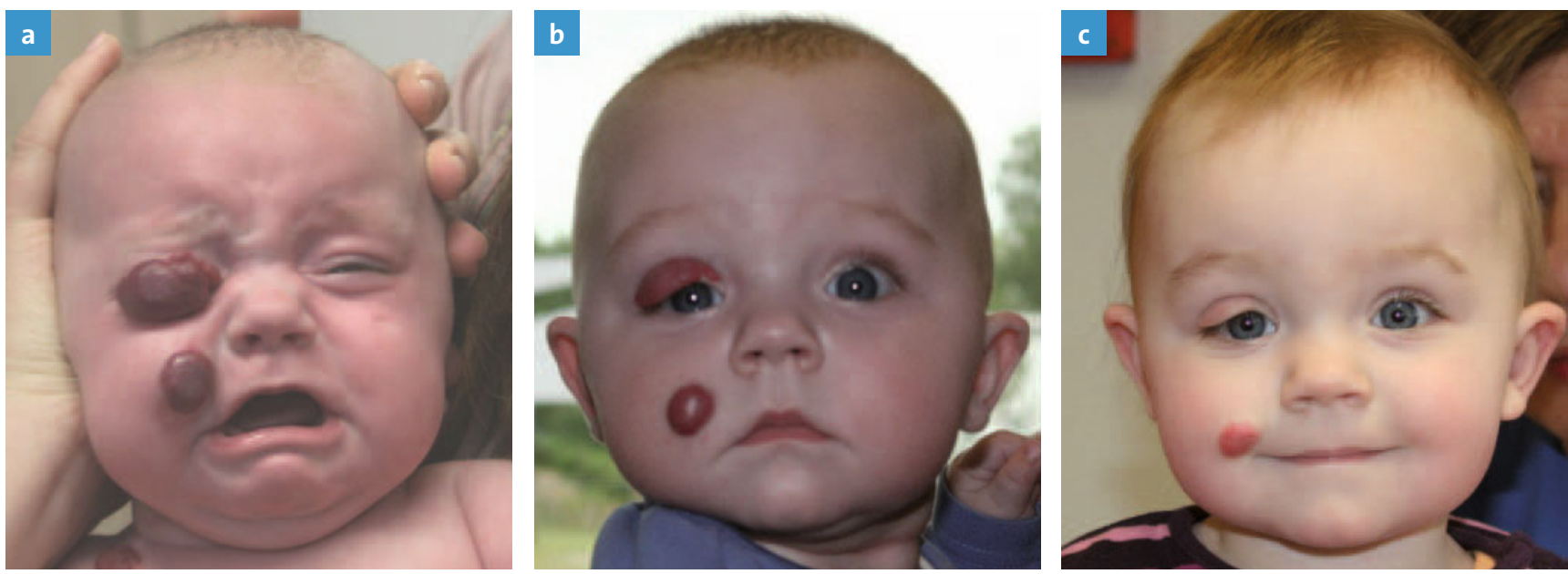

Therapieverlauf mit Propranolol: a: Kind mit Hämangiom im Bereich des rechten Auges und der Wange, das Auge kann nicht geöffnet werden; b: Zustand nach acht Wochen Behandlung mit Dociton ${ }^{\circledR}$; : Befund nach sieben Monaten Behandlung mit Dociton ${ }^{\circledR}$

\section{Sonderfall Adiponecrosis subcutanea}

- Eine Erkrankung bei Neugeborenen, die auf den ersten Blick mit Phlegmonen oder septischen Infiltraten verwechselt

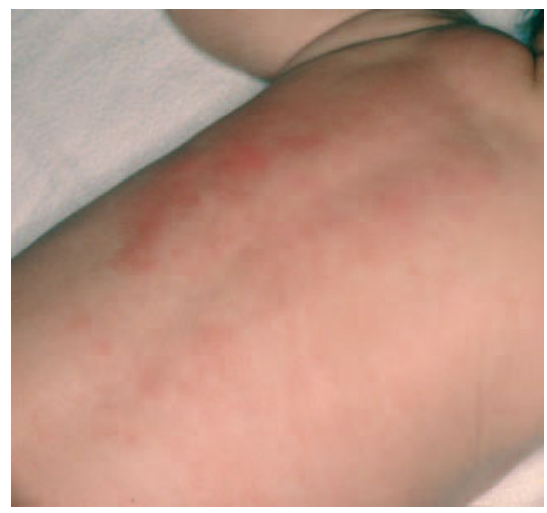

Zwei Fälle von Adiponecrosis subcutanea werden kann, ist die Adiponecrosis subcutanea. Bei den klinisch sonst unauffälligen Kindern fallen schmerzlose, oft livide

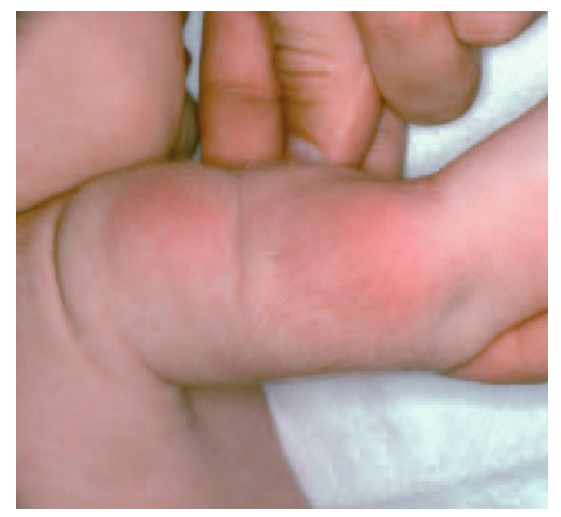

verfärbte flächige Hautareale auf, die sich derb und höckrig anfühlen. Diese Hautveränderungen, so Prof. Dr. Hansjörg Cremer, Heilbronn, entwickelten sich in der Regel erst einige Tage nach der Geburt. Prädilektionsstellen sind Rücken, Gesäß und proximale Extremitäten. Das Krankheitsbild tritt meist bei reifen Kindern auf und ist bedingt durch eine Druckschädigung im Mutterleib. Nur im Ausnahmefall wird es durch Asphyxie oder eine länger andauernde Unterkühlung verursacht. Im Verlauf von bis zu mehreren Monaten kommt es zur Rückbildung der Hautveränderungen, eine Behandlung ist nicht erforderlich.

af

Cremer H. Hautveränderungen in der Neugeborenenperiode 